\title{
Examining Vietnam's Success in Controlling COVID-19 Pandemic in Terms of People's Behavior
}

\author{
Ha Thu Luong* \\ School of Advanced Educational Programs, National Economics University, Hanoi, Vietnam \\ 207 Giai Phong Street, Hai Ba Trung District, Hanoi 100000, Vietnam \\ Email: haluongthu@neu.edu.vn \\ Ngoc Bich Le \\ School of Advanced Educational Programs, National Economics University, Hanoi, Vietnam \\ Hong Ha Ward, Nguyen Van Cu Street, Ha Long City, Quang Ninh Province 200000, Vietnam \\ Email: lebichngoc202000@gmail.com \\ Thuy Thu Trinh \\ School of Advanced Educational Programs, National Economics University, Hanoi, Vietnam \\ Hong Ha Ward, Nguyen Van Cu Street, Ha Long City, Quang Ninh Province 200000, Vietnam \\ Email: trinhtthuy2589@gmail.com \\ Thao Phuong Nguyen \\ School of Advanced Educational Programs, National Economics University, Hanoi, Vietnam \\ Cat Dai Ward, Le Chan District, Hai Phong 180000, Vietnam \\ Email: phuongthao101020@gmail.com
}

\begin{abstract}
To deal with an unprecedented pandemic known as COVID-19, every country has developed its own policies to prevent the expansion of Coronavirus. The purpose of this study is to investigate Vietnam's success in controlling the spread of COVID-19 epidemic from the perspective of people's behavior. This study applied the Health Belief Model developed by Don Nutbeam and Elizabeth (2004). An online survey engine (docs.google.com/forms) and an offline survey were employed to collect data from citizens in Hanoi, Ho Chi Minh City, Quang Ninh, Haiphong and other cities. The statistical analysis used 423 questionnaires from 450 respondents, mainly aged 18 to 35 . The results demonstrated that people's awareness of COVID-19 as well as their behaviors have contributed significantly to the successful efforts to prevent and control the disease in Vietnam.
\end{abstract}

Keywords: Covid-19 pandemic, controlling Covid-19, people's behavior, behavior, Vietnam

DOI: $10.7176 / \mathrm{EJBM} / 13-6-07$

Publication date:March $31^{\text {st }} 2021$

\section{Introduction}

According to the statistics of worldometers.info, updated on March 19, the total number of new Coronavirus infections causing acute respiratory infections (COVID-19) globally is 122,880,037 cases, of which 2,712,862 people died. Up to now, the epidemic has appeared and spread in 219 countries and territories. The COVID-19 epidemic has complicated developments in many countries, such as the US, France, Russia and Brazil, and has spread widely, with the increasing number of severely infected cases, especially in Europe. Serious disease developments have reappeared in some parts of the world, after a series of countries faced a new outbreak. The World Health Organization (WHO) predicts that the pandemic will continue to complicate and possibly last for the next 1-2 years. In Europe, Asia and America, the epidemic has not shown signs of decline with the emergence of many new virus variables, although many countries are speeding up vaccination.

Until March 19, the most severely affected country is the US with 554,104 deaths out of 30,425,787 total cases. Leading US health experts warned that, despite growing vaccination efforts, the number of infections may rise again due to the rapid growth of strain variables. They continue to call on people to seriously implement disease prevention measures such as wearing masks, washing hands with antiseptic and keeping contact distance. The other half of the hemisphere also witnessed complicated developments of the epidemic. China is the country to record the first cases of COVID-19 in the world with 27 cases of strange "pneumonia" diseases in Wuhan on December 31, 2019. As of March 19, 2021, there are 90,083 cases of infections and 4,636 cases of death recorded in China. In other Asian countries such as Korea, the number of untraceable cases continues to increase, raising concerns about the risk of an outbreak of another strong spread. According to the Korea Disease Control and Prevention Agency (KDCA), the number of cases that cannot be zoned and traced has increased by more than $25 \%$ in the past 2 weeks. The warmer weather and increasing demand for travel have partly affected the anti-epidemic work of the authorities. Meanwhile, the Japanese government decided to lift the emergency in the capital Tokyo 
and three neighboring prefectures from March 21. The disease context in Japan has improved significantly thanks to drastic measures by the government, including the declaration of emergency in 11 provinces and cities from January 2021 and prohibiting entry of all non-resident foreigners. In Europe, many countries continue to extend or maintain preventive measures for epidemic prevention and control. According to the Office of the World Health Organization (WHO) for Europe, the COVID-19 epidemic is becoming urgent in localities that have been very successful "in controlling the disease in the first 6 months of 2020." In the Balkans and Central Europe, hospital admissions and deaths are among the highest in the world. Many countries in Europe remain in full or partial blockade. In response to the third wave of COVID-19 outbreaks, the French government announced the order to re-block 16 provinces across the country, including the capital Paris. Meanwhile in Bulgaria, the number of COVID-19 cases and hospitalizations is on a strong rise, forcing the government to impose nationwide restrictions for 10 days, starting March 22. In the Southeast Asia area, as of March 15, the countries of the Association of Southeast Asian Nations (ASEAN) recorded an additional 12,121 cases of COVID-19 compared to one day ago, while the total number of deaths increased to 55,981 people. Indonesia continues to be the most serious outbreak of COVID-19 among ASEAN countries, with the highest number of infections and deaths in the region. Thailand, after witnessing a skyrocketing number of community infections in recent days, had to tighten epidemic prevention measures. At the meantime, in Cambodia, the cases are increasing rapidly and ominously, forcing authorities to block many provinces and cities, and issue urgent notices. The whole bloc is witnessing the epidemic developments of concern, complexity and potential risk of new COVID-19 outbreaks.

Being a neighbor with a 1,350 km long border of 7 provinces (Dien Bien, Lai Chau, Lao Cai, Cao Bang, Ha Giang, Lang Son, Quang Ninh), Vietnam faces challenges to prevent the epidemic from expanding rapidly and widely in the country, given its favorable trade situation, strongly operating transportations (air, waterway, road and railway). This once again puts Vietnam in a difficult situation when it comes to tracing the epidemiological history of the first cases and isolating and zoning off close contacts to minimize the spread among the community. Considering the current socio-economic condition, Vietnam is expected to encounter obstacles in coping with the pandemic. According to International Monetary Funds, in 2020, Vietnam GDP (nominal) per capita is US $\$ 3,498$, ranked 115 in the world and GDP (PPP) per capita is \$10,755, ranked 106th. Meanwhile, Vietnam GDP (nominal) in 2020 ranked 36th worldwide (US\$ 340,602) and GDP (PPP) ranked 23rd (\$1,047,318). Moreover, at the beginning of the year, Vietnam was stated as "having a weak health care system with a low budget and a large population" (Wikipedia, 2020). The health system of Vietnam ranks 104th among 195 countries. Due to the inability of extensive testing, Vietnam implements a strict 14-day quarantine policy and traces people who have been exposed to the virus. Instead of relying on medicine and technology, Vietnamese security apparatus has adopted a system of extensive public surveillance along with a well-deployed military force that is respected and trusted by the public. Vietnam's strategy is to deal with epidemics at a low cost, following the "dual goal" (to prevent and control disease, protect people's health while restoring and developing socio-economic in a "new normal" state) and most importantly, not risking public health. Up to now, Vietnam has experienced 4 major outbreaks, of which 2,571 cases were recorded (as of March 19, 2021) and ranked among the countries with the lowest COVID-19 mortality rate. All outbreaks are under control with human damage minimized. In addition, Vietnam is also the first country to lift social quarantine regulations in the context of the tense situations of the world. Despite having unfavourable conditions to face the COVID-19 pandemic, Vietnam is one of a few countries that have received the international press praises for success in disease control. According to a survey conducted in March 2020, Vietnam is the country with the highest satisfaction in the world about the government's response to the epidemic, followed by Argentina (61\%), Austria (58\%), Singapore (57\%), China (56\%), South Africa (56\%) (According to Wikipedia, 2020). It can be seen that the success of Vietnam's campaign against COVID-19 comes from many factors, in which the behavior of Vietnamese people plays a particularly important role. Therefore, research on factors influencing individual behaviors during the COVID-19 pandemic is developmental, contributing to the improvement of a more optimal epidemic prevention strategy in future to fight similar diseases.

\section{Literature review}

In the early 1950s, a group of four social psychologists (Hochbaum, Kegels, Leventhal, and Rosenstock) at the U.S. Public Health Service invented the Health Belief Model (HBM) to investigate the reasons for which people failed to participate in disease detection and prevention schemes. The model was primarily based on Kurt Lewin's idea of valence (1951), which explained that certain forces could enable or disable the possibility of behaviors. Lewin's work then led to the foundation of the belief-behavior relationship, which later inspired the birth of the HBM. Originally, the HBM consisted of three main categories of factor: individual perceptions (perceived susceptibility and perceived severity), modifying perceptions (demography, personality, socioeconomic status, existing knowledge, perceived threat and cues to action) and likelihood of action (perceived benefits and likelihood of behavior change).

In 2004, Don Nutbeam and Elizabeth Harris produced a simplified version of the HBM in the book "Theory In A Nutshell". In this version, the emphasis is placed on the "to perceive" elements as the writers believe that 
individuals will likely act for change if they find themselves to be exposed to a threat, or to benefit/suffer from an outcome.

The HBM states that health behavior changing is determined by some important factors including "perceived susceptibility, perceived severity, perceived benefits, perceived barriers, perceived threat and outcome expectations". The HBM is a reliable framework for studying health behaviors as it was cooperatively built by psychological researchers and health specialists. The HBM was made for the purpose of identifying the factors that are directly associated with a person's health belief, hence influencing their decision to make a change in health-related manners. Thereby, the application of the HBM was visible in a large number of medical studies, for example: "The Health Belief Model and Illness Behavior" - Kirscht (1974); "The Health Belief Model and Preventive Health Behavior" - Irwin M. Rosenstock (1974); "The Health Belief Model and Prediction of Dietary Compliance" - Becker, Maiman, Kirscht, Haefner and Drachman (1977), etc. More recently, in May 2020, HyunJeong Ban and Hak-Seon Kim published a research on Korean Medical Tourism based on the HBM's theoretical framework. The research was conducted in the tourism context to explore the impacts of foreigners' health beliefs to their intention of visiting Korean medical tourism.

In 2020, however, there is a more remarkable topic that is repeatedly discussed both in real life and on mass communication means: the COVID-19 pandemic. Starting in Wuhan, China, Coronavirus is now transcending the Chinese borders to other Asian, Western and European countries, leaving humanity in a chaos. In fFact, the world has been suffering from this disease for over a year and now, even with the presence of COVID-19 vaccines, it still shows no positive sign that this gloomy scene is terminating soon. Towards this situation, with the HBM as the foundation, Walrave, Waeterloos, and Ponnet have carried out research investigating the efficiency of a contact tracing app for people diagnosed with COVID-19 in Belgium (2020). The application was designed with a view of mapping out the region inflicted with COVID-19, thus better managing the booming of the disease. In the setting of Pakistan, Abdullah, Dias, Muley and Shahin also executed an academic paper to look into the impacts of COVID-19 on travel behavior and mode preferences.

Nevertheless, it is inarguably true that without the citizens' proper behavior, COVID-19 would not be undermined. The sad truth is that up until now, many countries in Europe and the America are still recording increasing cases of COVID-19 on a daily basis. On the other hand, regarding the combat against COVID-19, Vietnam is a prime example. Though Vietnam is only a developing country, by implementing strict procedures of social distancing and quarantine, we fearlessly battled COVID-19. This provokes our team to put under study the reasons why Vietnamese maintained their determination, despite all the hardships in terms of economics, to successfully contain the spread of COVID-19 in such a short period of time. Consequently, this study is dedicated to better clarify the factors that attribute to Vietnamese' positive manners to obey the Government's rules, which then led to Vietnam's success.

\section{Research model and structured survey questionnaire}

\subsection{Research model}

Based on the theoretical framework and summary of previous research, we prepared our research model of factors affecting people's implementation of preventive measures in Vietnam. Beside testing six existing factors from the available HBM model originated from "Theory In A Nutshell” (Don Nutbeam and Elizabeth Harris), we substitute the factor "Self-efficacy" for "Individual Behaviors" after examining Vietnam context. (Figure 1)

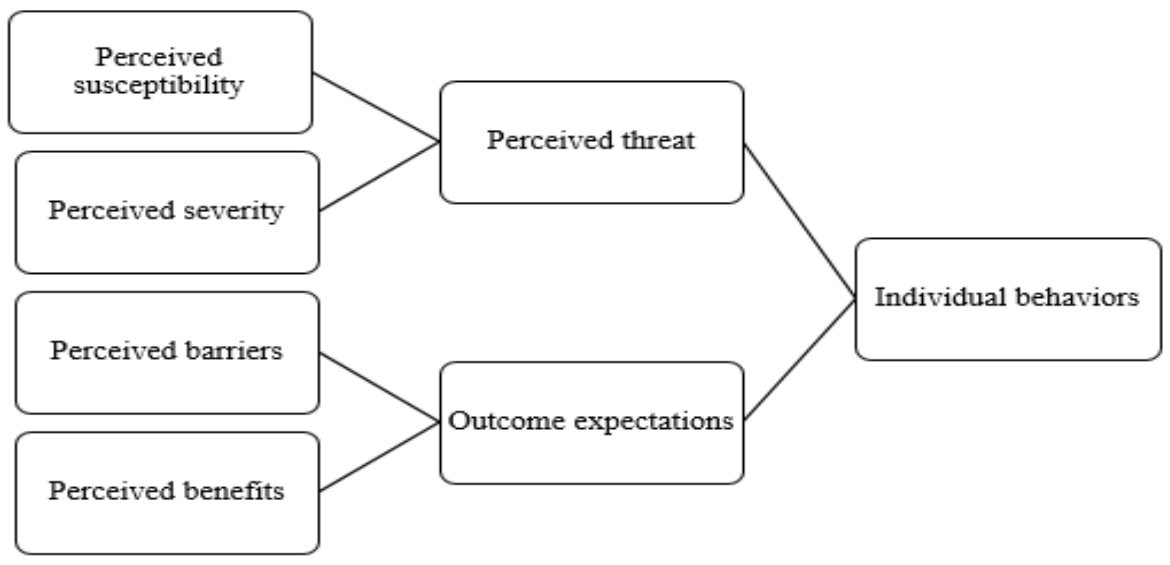

Figure 1. The Health Belief Model (Don Nutbeam and Elizabeth Harris, 2004)

It is said that HBM is one of the most prevailing models to explain people's health behavior, and the variables included in HBM have been stated as the key factors predicting people's health behaviors. The seven key constructs of the health belief model are identified as perceived susceptibility and perceived severity (two 
dimensions of "threat"), and perceived benefits and perceived barriers (the components of "outcome expectations"). More recent adaptations have added the concepts "individual behaviors," a stimulus to undertake behavior. Those components will be explained from 1 to 7 as followed.

Perceived Susceptibility: Perceived susceptibility refers to a person's sensitivities of the risk of acquiring an illness or disease. For example, people with high perceived susceptibility may admit that they are at risk for COVID-19 infection and the individual will be more likely to lean toward precautionary measures. Others may deny the possibility that they may have the disease.

Perceived Severity: HBM also assumes that people will be more inclined to protect themselves against the virus when their subjective perception of the seriousness of a health problem and its potential consequences is high. This concept refers to the factor Perceived Severity.

Perceived Benefits: Individual behavior is further determined by perceived benefits referring to the expected positive outcomes of doing one activity. Therefore, people who are more convinced by the importance of preventive measures (e.g., wearing masks, washing hands...) in preventing the virus would be more likely to perform those.

Perceived Barriers: This refers to a person's feelings on the obstacles to performing a health action. In the COVID-19 case, the person may view preventive measures as expensive, dangerous (e.g., side effects), unpleasant , time-consuming, or inconvenient.

Perceived Threat: Another key factor affecting people's health responses to the pandemic is Perceived Threat, which is a cognitive assessment of the prospect that a danger will affect them and how bad it will be if it does. Some researchers point out that the perceived threat positively correlates with healthy behavior, and the perception of threats would encourage people to act to reduce their risk.

Outcome Expectations: Outcome expectations, which reveal the beliefs in the consequences of an action on achieving a particular outcome, is also a chief determinant of behavior changing. If the outcome expectations of a person about the act to reduce the risk of the virus are positive, then they will be more inclined to do it.

Individual Behaviors: This factor, which refers to the changing of one's action, is the outcome of all the above components. For instance, people may accept to perform preventive measures after considering six other factors from the model.

\subsection{Structured survey questionnaire}

In order to address this study's objective, quantitative methods were employed. A structured survey questionnaire was used to investigate several factors: (a) Perceived Susceptibility, Severity, Benefits, Barriers; (b) Perceived Threat, Outcome Expectations; (d) Individual Behaviors and (e) Demographic information. For questionnaire validity and reliability, the Confirmatory Factor Analysis (CFA) and Cronbach's alpha test were employed. Therefore, the following hypotheses were established on a theoretical basis:

Perceived Susceptibility, Perceived Severity will have a positive effect on Perceived Threat. Meanwhile, Outcome Expectations will be positively affected by Perceived Benefits and negatively affected by Perceived Barriers. Perceived Threat and Outcome Expectations together will have a positive effect on Individual Behaviors.

The questions in the survey are focused on People's Responses to the Pandemic COVID-19, as shown in Table 1. The questionnaire of the HBM contained nine parts. The HBM is a comprehensive questionnaire, which helps to explain people's behavior to prevent a disease. Moreover, the basis of this model is encouraging participants to take part in so as to enhance their awareness of health beliefs, and leading to acceptable behavior. 
Table 1. Questionnaire of HBM

\begin{tabular}{|c|c|}
\hline & Variables / Items \\
\hline \multirow{5}{*}{1} & Perceived Susceptibility \\
\hline & I am at risk of being infected by the COVID-19 virus. (1) \\
\hline & I think COVID-19 can cause unbearable pain. (2) \\
\hline & If I get COVID-19, I could likely die. (2) \\
\hline & If I get COVID-19, I will get proper treatment in my country. (2) \\
\hline \multirow{4}{*}{2} & Perceived Severity \\
\hline & If I have COVID-19, I would have some inconvenience in my daily life. (2) \\
\hline & If I were infected by the COVID-19 virus, it would have important health consequences for me. (1) \\
\hline & If I were infected by the COVID-19 virus, it would have important health consequences for me. (1) \\
\hline \multirow{6}{*}{3} & Perceived Threat \\
\hline & I frequently find myself preoccupied with thinking about Coronavirus. (3) \\
\hline & There is little I can do to protect myself from Coronavirus. (3) \\
\hline & There is nothing I can do to defend myself and my beloved ones from the attack of Coronavirus. (3) \\
\hline & I worry that the threat of Coronavirus will never end. (3) \\
\hline & I believe the future is dark with respect to the threat of Coronavirus. (3) \\
\hline \multirow{7}{*}{4} & Perceived Benefits \\
\hline & The propagandas about COVID-19 will help me to better acknowledge the spread of the virus. (1) \\
\hline & $\begin{array}{l}\text { The effects of COVID-19 have made me become more cautious if I am in direct contact with other people. } \\
\text { (1) }\end{array}$ \\
\hline & $\begin{array}{l}\text { If I actively carry out the precautions (eg: washing my hands, wearing masks, social distancing), I will lower } \\
\text { my chances of being diagnosed withCOVID-19. (1) }\end{array}$ \\
\hline & The preventative behaviors will allow me to protect myself from the COVID-19 virus. (1) \\
\hline & By carrying out preventive behaviors, I will help public authorities to combat the COVID-19 virus. (1) \\
\hline & By carrying out preventive behaviors, similar diseases like COVID-19 can be prohibited in the future. (1) \\
\hline \multirow{5}{*}{5} & Perceived Barriers \\
\hline & Preventative behaviors for COVID-19 are time-consuming. (2) \\
\hline & $\begin{array}{l}\text { The maintenance of COVID-19 outbreak prevention actions (wearing a mask, washing hands, isolating } \\
\text { themselves...) is complex and a hindrance in everyday life. (2) }\end{array}$ \\
\hline & Reporting personal schedules to the Government invades the privacy of its residents. (1) \\
\hline & $\begin{array}{l}\text { The COVID-19 pandemic will create tensions between individuals who are infected by the COVID-19 virus } \\
\text { and those who are not. (1) }\end{array}$ \\
\hline \multirow{6}{*}{6} & Outcome Expectations \\
\hline & $\begin{array}{l}\text { I believe that if I comply with the COVID-19 prevention regulations, I will feel less stressed and pressured. } \\
\text { (4) }\end{array}$ \\
\hline & $\begin{array}{l}\text { The compliance with the COVID-19 prevention regulations will help me to avoid negative effects on my } \\
\text { respiratory system. (4) }\end{array}$ \\
\hline & $\begin{array}{l}\text { The compliance with the COVID-19 prevention regulations will reduce my risk of getting the Coronavirus. } \\
\text { (4) }\end{array}$ \\
\hline & The compliance with the anti COVID-19 rules will help me to reunite with my family and friends soon. (4) \\
\hline & If I seriously stick to the anti COVID-19 measures, I hope life will soon return to its normal state. (4) \\
\hline \multirow{6}{*}{7} & Individual Behaviors \\
\hline & $\begin{array}{l}\text { I proactively comply with the prevention measures of COVID-19 and the regulations of the Government on } \\
\text { social segregation. (2) }\end{array}$ \\
\hline & I will consider going to a health center for a checkup if I suspect I have COVID-19. (2) \\
\hline & $\begin{array}{l}\text { I am willing to go to the medical center when I suspect myself of being infected with COVID-19, even if it } \\
\text { could make me stay in quarantine. (2) }\end{array}$ \\
\hline & I will remind people to get check-ups at the health care center when they have symptoms of COVID-19. (2) \\
\hline & $\begin{array}{l}\text { I will report to the authorities when I find someone violating the COVID-19 epidemic prevention } \\
\text { regulations. (2) }\end{array}$ \\
\hline
\end{tabular}

(Source: (1): Walrave, Waeterloos, Ponnet (2020), (2): Hyun-Jeong Ban and Hak-Seon Kim (2020), (3): Irshad, Khattak, Hassan, Majeed and Bashir (2020), (4): Kaigang Li, Dong-Chul Seo \& Mohammad R. Torabi (2014))

The questions in the survey were taken from a prior study of individual's behavior in a health crisis context with HBM, and the validity of the questionnaire was proven by the previous studies. The study used a convenience online and offline sampling methods. As it targets people living in many other cities in Vietnam, such as Hanoi, 
Ho Chi Minh City, Quang Ninh and Hai Phong Province, an online questionnaire was used. We also employed an offline survey. Questionnaires from online survey engine (docs.google.com/forms) and offline handouts were distributed from 15 December 2020 to 29 January 2021.

The survey was conducted on Vietnamese residents. The questionnaire was conducted in Vietnamese, and 50 questionnaires were completed by translating English into Vietnamese with the help of experts. Then, 450 copies were collected after distributing online and offline questionnaires, and only 423 copies were used after 27 unsatisfactory responses, which were not completed or had the same answer for every question, were discarded. SPSS 22.0 were used for the analysis of the investigated data.

\section{Research results}

\subsection{Research rescription}

To carry out our study, we followed a quantitative method. A sample of 450 questionnaires from respondents were collected through online and offline surveys. Our respondents were mainly from big cities of Vietnam (Hanoi, Ho Chi Minh City, Quang Ninh, Hai Phong), aged 18 to 35. The method of self-administered survey was employed for this study. For online survey, we used an online survey engine (docs.google.com/forms) while for offline survey, a trained data-collection team handed questionnaires to each respondents and later assembled the completed surveys.

In each city, several living quarters were selected, and a random sample of respondents was pulled from each living quarters. To enhance the representativeness for the sample, other demographic characteristics were considered (e.g., age, gender, occupation, average monthly income). We also checked the respondents' answers regarding the number of items on the questionnaire. Those respondents who did not fill every item or completed dishonestly were dropped. The final sample comprised 423 subjects ( 215 from Hanoi, 104 from Ho Chi Minh City, 53 from Haiphong, 37 from Quang Ninh and 14 from other cities). The majority of the people who participated in our surveys is recorded to be female (60\%), and the remaining $40 \%$ is male. $50 \%$ of those are youngsters aged between 19 and 22, while around $30 \%$ belong to the sector from 23 to 40 years old. As a matter of fact, the most commonly seen occupation in this dataset is "university/college students" with an average monthly income of under 5 million VND. This is followed by "employees in administrative and non-business units or state enterprises" and "employees in private or foreign enterprises", whose earnings fluctuate between 5 and 50 million per month.

\subsection{Quantitative Research}

Table 2. Cronbach's Alpha

\begin{tabular}{|c|l|c|}
\hline & \multicolumn{1}{|c|}{ Variables / Items } & Cronbach's Alpha \\
\hline 1 & Perceived Susceptibility & 0.614 \\
\hline 2 & Perceived Severity & 0.803 \\
\hline 3 & Perceived Threat & 0.763 \\
\hline 4 & Perceived Benefits & 0.884 \\
\hline 5 & Perceived Barriers & 0.751 \\
\hline 6 & Outcome Expectations & 0.886 \\
\hline 7 & Individual Behaviors & 0.866 \\
\hline
\end{tabular}

Cronbach's Alpha is a test to analyze and evaluate the reliability of the scale. The purpose of Cronbach's Alpha is to find out whether items in the same group are measuring the same concept. The contribution of the items is reflected through the correlation coefficient of the total variable, or as known as "Corrected Item - Total Correlation" in SPSS. Thanks to that, we are capable of eliminating the inconsistent variables in our research model. If Cronbach's Alpha value is greater than 0.8 , it is a good scale; from 0.7 to 0.8 is usable; from 0.6 or more is accepted when the research concept is new (Nunally, 1978; Peterson, 1994; Slater, 1995). As can be seen from our data analysis results, the Cronbach's Alpha values for all the items involved range from 0.6 to 0.9 , thus this scale is reliable.

\section{EFA analysis for independent factors}

While we use the Cronbach's Alpha method to assess the reliability of the scale, the Exploratory Factor Analysis (EFA method, referred to as the EFA method) helps us to evaluate the validity of the items. Discovery factor analysis EFA is used to reduce a set of $\mathrm{x}$, turning observations into a set $\mathrm{F}$ (with $\mathrm{F}<\mathrm{x}$ ) of more meaningful factors.

The first round of EFA analysis resulted in the elimination PSu 3 because its loading factor was lower than 0.5. Therefore, we saw the need in carrying out another round of EFA analysis. This time, we noticed that the resulting factor met the satisfactory levels in all the criteria. The statistics for KMO is 0.871 , which is between the accepted range from $0.5<\mathrm{KMO}<1$. Meanwhile, Bartlett's results have Sig. $=0.000$, meaning that all the factors are well-correlated with one another. 4 factors need to be extracted. Rotation Cumulative Sum of Squared Loading Value displayed that 4 factors explained $60.130 \%$ of total variance. The number of all loading factors was also greater than 0.5 . At this point, the authors have identified 4 key groups of independent factors that will be instead 
of the 4 potential variables as the original hypothetical model.

\section{EFA analysis for dependent factors}

Based on analysis results, the three scales of Perceived Threat, Outcome Expectations and Individual Behaviors separate into three groups. Authors included all of the dependent components and extracted 3 dependent components, similar to the initial plan. Bartlett's results have Sig. $=0.000$, the number of factors extracted is 4 factors, total variance extracted of $65.454 \%$, the number of all loading factors was greater than 0.5 .

Independent Factors: (X1) Perceived Susceptibility, (X2) Perceived Severity, (X3) Government Communications, (X4) Perceived Benefits, (X5) Perceived Barriers, (X6) Trust in Government. Dependent Factor: (Y1) Perceived Threat, (Y2) Outcome Expectations, (Y3) Individual Behaviors.

Correlation and Regression

The results of Pearson's correlation analysis show that there exist linear correlations between the dependent variable $\mathrm{Y} 1$ and the independent variables $\mathrm{X} 1, \mathrm{X} 2$; the dependent variable $\mathrm{Y} 2$ and $\mathrm{X} 3, \mathrm{X} 4$; and the dependent variable Y1, Y2, Y3 and the independent variables X1, X2, X3, X4.

Table 3. The regression result for Perceived Susceptibility, Perceived Severity and Perceived Threat

\begin{tabular}{|c|c|c|c|c|c|c|c|}
\hline \multicolumn{8}{|c|}{ Coefficients $^{\mathrm{a}}$} \\
\hline Model & \multicolumn{2}{|c|}{ Unstandardized Coefficients } & \multirow{2}{*}{$\frac{\text { Standardized Coefficients }}{\text { Beta }}$} & \multirow[t]{2}{*}{$\mathrm{t}$} & \multirow[t]{2}{*}{ Sig. } & \multicolumn{2}{|c|}{ Collinearity Statistics } \\
\hline & $\mathrm{B}$ & Std. Error & & & & Tolerance & VIF \\
\hline (Constant) & 1.722 & .259 & & 6.650 & .000 & & \\
\hline $\mathrm{PSu}$ & .102 & .055 & .095 & 1.872 & .062 & .776 & 1.289 \\
\hline PSe & .383 & .057 & .341 & 6.712 & .000 & .776 & 1.289 \\
\hline
\end{tabular}

a. Dependent variable: (Y1) Perceived Threat

Results of linear regression analyze the effects between the factors affecting individual behaviors during the COVID-19 pandemic in Table 3, Table 4 and Table 5 with a 5\% significance indicate the relationship of 4 independent variables (X1) Perceived Susceptibility (Sig.=0.000), (X2) Perceived Severity (Sig.=0.000), (X3) Perceived Benefits (Sig. $=0.000),(\mathrm{X} 4)$ Perceived Barriers $($ Sig. $=0.000)$ and two other dependent variables (Y1) Perceived Threat (Sig. $=0.000)$ and (Y2) Outcome Expectations (Sig. $=0.000)$ to dependent variable (Y3) Individual Behaviors (Sig. $=0.000$ ).

The first regression model is the analysis of dependent variable (Y1) Perceived Threat and two independent variables (X1) Perceived Susceptibility, (X2) Perceived Severity: the coefficient adjusted $\mathrm{R}^{2}$ is 0.152 , which means that the linear regression model was built in accordance with the data set at $15.2 \%$. Next, the analysis results show that the Sig value of the F-test is very small $\left(0.000^{\mathrm{b}}\right)$ and VIF coefficient of the independent variables is less than 2 , hence no collinearity phenomenon occurs.

The regression model is the analysis of dependent variable (Y2) Outcome Expectations and two independent variables (X3) Perceived Benefits, (X4) Perceived Barriers: the coefficient adjusted $\mathrm{R}^{2}$ is 0.514 , which means that the linear regression model was built in accordance with the data set at $51.4 \%$. Next, the analysis results show that the Sig value of the F-test is very small $\left(0.000^{b}\right)$ and VIF coefficient of the independent variables is less than 2 , hence no collinearity phenomenon occurs.

Table 4. The regression result for Perceived Benefits, Perceived Barriers and Outcome Expectations

\begin{tabular}{|c|c|c|c|c|c|c|c|}
\hline \multicolumn{8}{|c|}{ Coefficients $^{\mathrm{a}}$} \\
\hline Model & \multicolumn{2}{|c|}{$\begin{array}{l}\text { Unstandardized } \\
\text { Coefficients }\end{array}$} & \multirow{2}{*}{$\begin{array}{c}\text { Standardized } \\
\text { Coefficients }\end{array}$} & \multirow[t]{2}{*}{$\mathrm{t}$} & \multirow[t]{2}{*}{ Sig. } & \multicolumn{2}{|c|}{ Collinearity Statistics } \\
\hline & B & Std. Error & & & & Tolerance & VIF \\
\hline (Constant) & 1.375 & .186 & & 7.385 & .000 & & \\
\hline $\mathrm{PBa}$ & -.047 & .023 & -.070 & -2.006 & .045 & .941 & 1.063 \\
\hline $\mathrm{PBe}$ & .714 & .036 & .698 & 19.952 & .000 & .941 & 1.063 \\
\hline
\end{tabular}

a. Dependent variable: (Y2) Outcome Expectations

The regression model is the analysis of dependent variable (Y3) Individual Behaviors and two dependent variables (Y1) Perceived Threat, (Y2) Outcome Expectations: the coefficient adjusted $\mathrm{R}^{2}$ is 0.445 , which means that the linear regression model was built in accordance with the data set at $44.5 \%$. Next, the analysis results show that the Sig value of the F-test is very small $\left(0.000^{\mathrm{b}}\right)$ and VIF coefficient of the independent variables is less than 2 , hence no collinearity phenomenon occurs. 
Table 5. The regression result for Perceived Threat, Outcome Expectations and Individual Behaviors

\begin{tabular}{|c|c|c|c|c|c|c|c|}
\hline \multicolumn{9}{|c|}{ Coefficients $^{\mathbf{a}}$} \\
\hline Model & Unstandardized Coefficients & Standardized Coefficients & $\mathrm{t}$ & Sig. & \multicolumn{2}{|c|}{ Collinearity Statistics } \\
\hline & $\mathrm{B}$ & Std. Error & Beta & & & Tolerance & VIF \\
\hline (Constant) & 1.783 & .165 & & 10.782 & .000 & & \\
\hline PT & .073 & .030 & .091 & 2.420 & .016 & .922 & 1.085 \\
\hline OE & .566 & .034 & .637 & 16.868 & .000 & .922 & 1.085 \\
\hline
\end{tabular}

a. Dependent variable: (Y3) Individual Behaviors

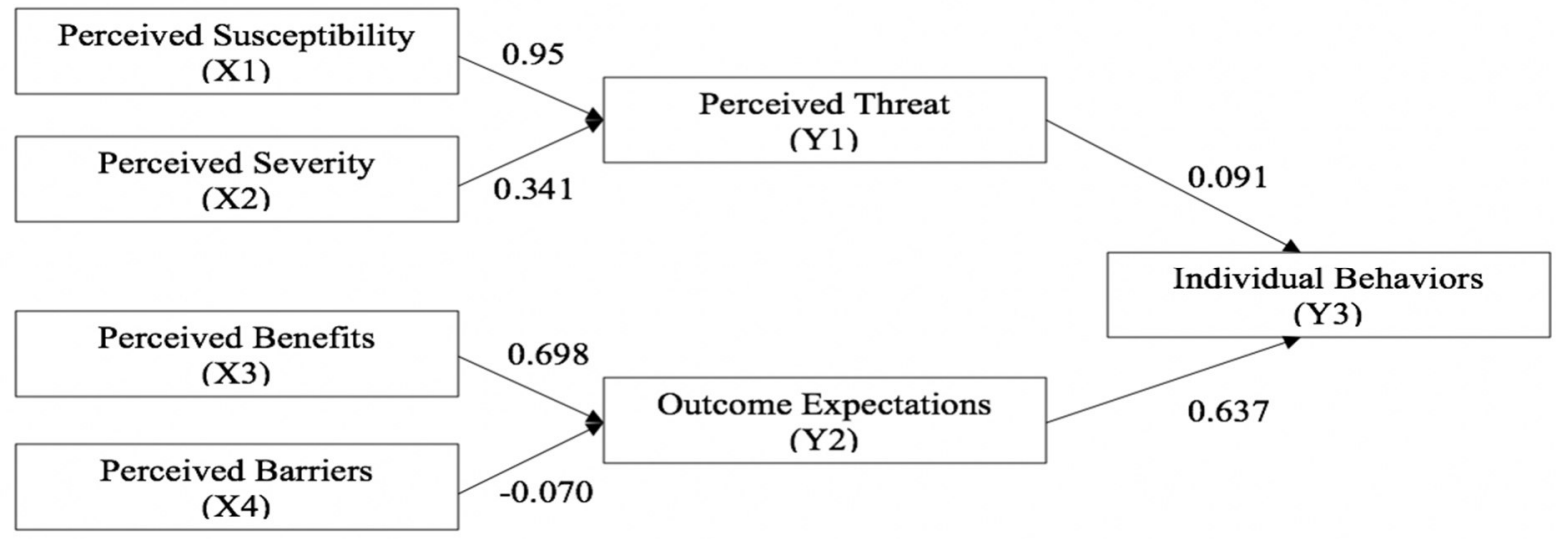

Figure 2. Model of research on factors affecting individual behaviors during COVID-19 pandemic in Vietnam.

The regression results assessing the impact of 2 factors on (Y1) Perceived Threat is as followed:

$\mathrm{Y} 1=0.95(\mathrm{X} 1)+0.341(\mathrm{X} 2)$

This indicates that with the significance of $5 \%$, there are 2 factors affecting one's perception about Perceived Threat. The impact levels of 2 factors in descending order are:

- (X2) Perceived Severity: $\beta=0.341$

- (X1) Perceived Susceptibility: $\beta=0.095$

The standardized coefficients ßeta $>0$ show a positive relationship between the independent variables and Perceived Threat. Factor (X2) Perceived Severity is assessed as having the stronger impact on Perceived Threat, while factor (X1) Perceived Susceptibility is assessed as having the weaker impact on Perceived Threat than (X1).

The regression results assessing the impact of 2 factors on (Y2) Outcome Expectations is as followed:

$\mathrm{Y} 2=0.698(\mathrm{X} 3)+-0.070(\mathrm{X} 4)$

This indicates that with the significance of $5 \%$, there are 2 factors affecting one's perception about Outcome Expectations. The impact levels of 2 factors in descending order are:

- Perceived Benefits: $\beta=0.698$

- Perceived Barriers: $\beta=(-0.070)$

The standardized coefficients Beta $>0$ of (X3) show a positive relationship between the independent variable (X3) Perceived Benefits and Outcome Expectations. Meanwhile, the standardized coefficients Beta $<0$ of (X4) Perceived Barriers show that (X3) and Outcome Expectations enjoy a negative relationship. Factor (X3) Perceived Benefits is assessed as having the stronger impact on Outcome Expectations, while factor (X4) Perceived Barriers is seen as having the weaker impact on Outcome Expectations than (X3).

The regression results assessing the impact of 2 factors on (Y3) Individual Behaviors is as followed:

$\mathrm{Y} 3=0.091(\mathrm{Y} 1)+0.637(\mathrm{Y} 2)$

This indicates that with the significance of $5 \%$, there are 2 factors affecting one's perception about Individual Behaviors. The impact levels of 2 factors in descending order are:

- Outcome Expectations: $\beta=0.637$

- $\quad$ Perceived Threat: $\beta=0.091$

The standardized coefficients Beta $>0$ show a positive relationship between the independent variables and Individual Behaviors. Factor (Y2) Outcome Expectations is assessed as having the stronger impact on Individual Behaviors, while factor (Y1) Perceived Threat is assessed as having the weaker impact on Individual Behaviors than Outcome Expectations (Y2). 


\section{Conclusion and recommendation}

\subsection{Conclusion}

- $\quad$ The EFA results show that Perceived Susceptibility and Perceived Severity share a positive relationship with Perceived Threat. Perceived Severity is assessed as having the stronger impact on Perceived Threat, while Perceived Susceptibility is assessed as having the weaker impact on Perceived Threat than Perceived Susceptibility.

- Based on the regression analysis, Perceived Benefits and Outcome Expectations have a positive relationship, while on the contrary, there exists a negative relationship between Perceived Barriers and Outcome Expectations. As a result, Perceived Benefits has the stronger impact on Outcome Expectations, and Perceived Barriers has the weaker impact on Outcome Expectations.

- The regression results on the impact of 2 factors on Individual Behaviors show that both Outcome Expectation and Perceived Threat have a positive relationship with Individual Behaviors. However, Outcome Expectations is assessed as having the stronger impact on Individual Behaviors, while Perceived Threat is assessed as having the weaker impact on Individual Behaviors.

\subsection{Recommendation}

\section{For government agency}

- $\quad$ Raising citizens' awareness about maintaining preventative behaviors to battle the COVID-19 pandemic and other similar diseases.

- Implementing heavy fines on individuals who do not seriously adhere to the Government's rules on quarantine and preventative behaviors, and those who illegally smuggle foreigners into the realm of Vietnam during the COVID-19 pandemic.

- Providing the needed medical equipment and staff for the localities that are encountering with COVID19 pandemic.

For public places (hospitals, restaurants, schools, parks, malls, supermarkets, etc.)

- $\quad$ Setting up guards to make sure that everybody is wearing masks while going out.

- People should be 2 meters apart from one another.

\section{For people}

- All citizens living in Vietnam would have to strictly comply with the Government's rules on preventative behaviors and quarantine during COVID-19 pandemic.

- In case of finding out that there are people who break the law of preventative behaviors and quarantine, please report to the authorities immediately.

\subsection{Limitations and further research}

- Research revolving around the topic of citizens' behavior during the COVID-19 pandemic is rather new, therefore the amount of material available for consulting is limited.

- The scope of this study is majorly based in Hanoi, Haiphong, Quang Ninh and Ho Chi Minh City developing cities in Vietnam. As a consequence, the results gathered could be subjective as citizens living in those areas are comparatively more advantaged and knowledgeable than those in isolated and remote areas. Hence, the research's findings may be subjective and unfortunately, not truly reflecting the opinions of all the citizens living in Vietnam. However, these findings could be utilized to make comparisons to the attitudes of citizens in other localities of Vietnam, or more broadly in other countries and regions.

- In the case of Vietnam, the Health Belief Model should also include factors relating to the Government's impacts on the citizens' awareness and behaviors towards COVID-19 pandemic, namely "Trust in Government" and "Government Communications".

\section{REFERENCES}

1. Chew, F.; Palmer, S.; Slonska, Z.; Subbiah, K, 'Enhancing health knowledge, health beliefs, and health behavior in Poland through a health promoting television program series', May-June 2002. Available at : https://pubmed.ncbi.nlm.nih.gov/12166872/

2. Fossum, B. (2003). 'Communication in the Health Service: Two Examples, ReproPrint AB, Stockholm, 2003'. Available at: Major elements of the Health Belief Model. From Nutbeam \& Harris [68]. | Download Scientific Diagram (Accessed: 10 March 2021)

3. Hyun-Jeong Ban and Hak-Seon Kim (2020), 'Applying the Modified Health Belief Model (HBM) to Korean Medical Tourism', 22 May 2020. Available at: https://www.ncbi.nlm.nih.gov/pmc/articles/PMC7277940/

4. Ministry of Health (2021), 'Prime Minister Nguyen Xuan Phuc presides over the national online meeting on COVID-19', Ministry of Health, 17 March 2021. Available at: https://moh.gov.vn/tin-noi-bat//asset_publisher/3Yst7YhbkA5j/content/thu-tuong-nguyen-xuan-phuc-chu-tri-hop-truc-tuyen-toan-quoc-ve- 
covid-19 (Accessed: 20 March 2021)

5. Quynh Duong (2021), 'The proportion of people infected with COVID-19 is still rising sharply in 14 US states', Hanoimoi, 19 March 2021. Available at: http://www.hanoimoi.com.vn/tin-tuc/The-gioi/993927/ty-lenguoi-mac-covid-19-van-tang-manh-tai-14-bang-cua-my (Accessed: 20 March 2021)

6. Rogers, R. W. (1975), 'A protection motivation theory of fear appeals and attitude change', The Journal of Psychology, 05 June 1975. Available at: https://www.tandfonline.com/doi/abs/10.1080/00223980.1975.9915803

7. The Vietnamese news agency (2021), 'COVID-19 updates on March 16: The world has over 120.7 million cases; WHO recommends that the AstraZeneca vaccine be continued', Vietnam Financial Times, 16 March 2021. Available at: http://thoibaotaichinhvietnam.vn/pages/quoc-te/2021-03-16/covid-19-toi-sang-16-3-thegioi-tren-1207-trieu-ca-benh-who-khuyen-nghi-tiep-tuc-dung-vaccine-astrazeneca-101068.aspx (Accessed: 20 March 2021) 